\title{
APPL proteins promote TGF $\beta$-induced nuclear transport of the TGF $\beta$ type I receptor intracellular domain
}

\author{
Jie Song ${ }^{1, *}$, Yabing $\mathrm{Mu}^{1, *}$, Chunyan $\mathrm{Li}^{2}$, Anders Bergh ${ }^{1}$, Marta Miaczynska ${ }^{3}$, \\ Carl-Henrik Heldin ${ }^{4}$, Marene Landström ${ }^{1}$ \\ $\mathbf{1}_{\text {Medical Biosciences, Umeå University, Umeå, Sweden }}$ \\ 2 Implant Center, Stomatological Hospital, Jilin University, Changchun, China \\ 3 International Institute of Molecular and Cell Biology, Laboratory of Cell Biology, Warsaw, Poland \\ 4 Ludwig Institute for Cancer Research Ltd, Science for Life Laboratory, Uppsala University, Uppsala, Sweden \\ *These authors contributed equally to this work
}

Correspondence to: Marene Landström, e-mail: marene.landstrom@medbio.umu.se

Keywords: APPL proteins, prostate cancer, signal transduction, tumour necrosis factor receptor-associated factor 6, transforming growth factor $\beta$

Received: October 07, $2015 \quad$ Accepted: November 09, 2015

Published: November 18, 2015

\section{ABSTRACT}

The multifunctional cytokine transforming growth factor- $\beta$ (TGF $\beta$ ) is produced by several types of cancers, including prostate cancer, and promote tumour progression in autocrine and paracrine manners. In response to ligand binding, the TGF $\beta$ type I receptor (T $\beta R I)$ activates Smad and non-Smad signalling pathways. The ubiquitinligase tumour necrosis factor receptor-associated factor 6 (TRAF6) was recently linked to regulate intramembrane proteolytic cleavage of the TBRI in cancer cells. Subsequently, the intracellular domain (ICD) of T $\beta R I$ enters in an unknown manner into the nucleus, where it promotes the transcription of pro-invasive genes, such as MMP2 and MMP9. Here we show that the endocytic adaptor molecules APPL1 and APPL2 are required for TGF $\beta$-induced nuclear translocation of T $\beta R I-I C D$ and for cancer cell invasiveness of human prostate and breast cancer cell lines. Moreover, APPL proteins were found to be expressed at high levels in aggressive prostate cancer tissues, and to be associated with T $\beta R I$ in a TRAF6-dependent manner. Our results suggest that the APPL-T $\beta R I$ complex promotes prostate tumour progression, and may serve as a prognostic marker.

\section{INTRODUCTION}

Prostate cancer is the second most common cause of cancer-related death among men in the Western world [1]. High levels of transforming growth factor $\beta$ (TGF $\beta$ ) is known to be associated with a poor prognosis for the patients [2]. Members of the TGF $\beta$ family regulate cell proliferation, differentiation, apoptosis, migration and the epithelial-mesenchymal transition (EMT), and are therefore important for embryogenesis and tissue homeostasis in adults, as well as for cancer progression. TGF $\beta$ signals by binding to type I and type II serine/ threonine kinase receptors (T $\beta$ RI and T $\beta$ RII, respectively). After ligand-induced formation of heterotetrameric complexes of T $\beta$ RII and T $\beta$ RI, T $\beta$ RII phosphorylates the glycine-serine (GS)-rich domain of T $\beta R I$, leading to conformational changes and activation of the kinase activity of T $\beta$ RI. Activated T $\beta$ RI induces phosphorylation of the C-terminal SSXS motif of receptor-activated SMADs (SMAD2 and 3), which then translocate to the nucleus where they regulate the expression of target genes together with the common mediator SMAD4 [3-7]. TGF $\beta$ also signals via non-SMAD pathways, including Erk, JNK and p38 MAP-kinase pathways, phosphatidylinositol 3-kinase (PI3K) and the tyrosine kinase Src [8, 9]. For activation of the TGF $\beta$-activated kinase 1 (TAK1) and the downstream $\mathrm{p} 38 / \mathrm{JNK}$ pathways that promote apoptosis and EMT, the tumour necrosis factor-associated factor 6 (TRAF6) is essential $[10,11]$. TRAF6 also promotes the proteolytic cleavage of T $\beta$ RI and the release of the 
intracellular domain (ICD) that translocates to the nucleus in an unknown manner, and drives an invasiveness programme $[12,13]$.

TGF $\beta$ receptor signalling is regulated by both clathrin-mediated endocytosis, which is used by many cell-surface receptors such as the epidermal growth factor (EGF) receptor and $\mathrm{G}$ protein-coupled receptors, as well as by lipid raft/caveolin-mediated endocytosis [14]. In clathrin-dependent endocytosis, TGF $\beta$ receptors are internalized to phosphatidylinositol-3-phosphate (PI3P)enriched, early endosome antigen-1 (EEA1)-positive endosomes, where they interact with the SMAD anchor for receptor activation (SARA) to induce the canonical SMAD-dependent signalling pathway [15]. From the early endosome, TGF $\beta$ receptors can be recycled back to the cell surface in the absence of ligand by entering Rab11-positive endosomes [16, 17]. In lipid raft/caveolaedependent endocytosis, the association of TGF $\beta$ receptors with SMAD7 and the ubiquitin ligase Smurf2 facilitates the ubiquitin-dependent degradation of the receptors by their internalization into caveolin-1-positive vesicles [15].

The small GTPase Rab5 is a key regulator of the early steps of endosomal sorting and is implicated in transducing TGF $\beta$ signals [18]. Rab5 interacts with and regulates the activities of EEA1 and PI3K [19, 20]. APPL1 and APPL2 are Rab5 effector proteins and are multifunctional adaptor proteins that contain an N-terminal bin1/amphiphysin/Rvs 167 (BAR) domain, a pleckstrin homology $(\mathrm{PH})$ domain, and a C-terminal phosphotyrosine binding (PTB) domain [21]. APPL endosomes can act as precursors of classical EEA1positive endosomes, and depletion of PI-3-phosphate leads to an expansion of the APPL compartments [22]. APPL1 is implicated in several signalling pathways, such as the EGF [23], androgen [24], and NF- $\mathrm{B}$ [25] pathways, but has not previously been linked to TGF $\beta$ signalling. Upon EGF stimulation, APPL1 is released from early endosomes and translocates to the nucleus, where it associates with the nucleosome remodelling and histone deacetylation machinery $[23,26,27]$. In addition, APPL1 interacts with signalling proteins, including Akt [21] and PI3K [21, 24]. Through its varied interactions, APPL1 has been reported to mediate apoptosis [28], cell proliferation [23, 26], as well as the endosomal localization of proteins [29, 30]. APPL1 and Rab5a have recently been found to be overexpressed in lung adenocarcinoma [31], but the precise role of APPL proteins in malignancies is still unknown.

To elucidate the molecular mechanisms mediating invasion of prostate cancer cells, we investigated the role of APPL proteins in TGF $\beta$-induced signal transduction. In this report, we identify APPL1 as a T $\beta R I-$ and PKC $\zeta$ associated protein and show that APPL1 and APPL2 are required for the nuclear translocation of T $\beta$ RI-ICD, and thereby promote progression of prostate cancer cells.

\section{RESULTS}

\section{Nuclear accumulation of the ICD of TßRI is dependent on APPL proteins}

We have previously reported that T $\beta R I$ undergoes proteolytic cleavage in cancer cells, whereby TRRIICD is released from the membrane and is translocated into the nucleus, however, the molecular mechanism involved is not known $[12,13]$. As APPL proteins act as adaptor proteins that facilitate cargo trafficking from the endosomal membranes to the nucleus in response to EGF $[24,32]$, we explored the possibility that APPL proteins are involved in the TGF $\beta$-induced nuclear translocation of T $\beta R I-I C D$.

We investigated the subcellular localization of endogenous APPL1 and TRRI-ICD in human prostate cancer PC-3U cells using immunofluorescence staining and confocal imaging. Interestingly, stimulation by TGF $\beta$ for 30 minutes induced the co-localization of APPL1 and T $\beta R I-I C D$ in the nucleus, as visualized by staining with antibodies recognizing APPL1 and the C-terminal part of TRRI, respectively $[12,23]$. By contrast, almost no T $\beta R I-I C D$ translocated into the nuclei of TGF $\beta$-treated cells after knockdown of endogenous APPL1 and APPL2 (Figure 1A). Next, we analyzed the localization of a fusion protein in which GFP was linked to the C-terminus of T $\beta$ RI-ICD. GFP-T $\beta R I-I C D$ co-localized with endogenous APPL1 in PC-3U nuclei after TGF $\beta$ treatment for 30 minutes, whereas there was no significant nuclear accumulation of GFP-T $\beta$ RI-ICD when APPL1 and APPL2 expression was silenced (Figure 1B). To further explore the possibility that TGF $\beta$ induces a complex between APPL1 and TRRI-ICD, we performed a proximity ligation assay (PLA) [33]. We found that TGF $\beta$ stimulation induced a complex of APPL1 and TRRI in cells, as shown by the red dots in Figure 1C; as expected, no such signals were seen when APPL1/2 was knocked down by siRNA (Figure 1C).

To further confirm that APPL proteins participate in the nuclear translocation of T $\beta$ RI-ICD, we performed nuclear fractionation of cell lysates from TGF $\beta$-treated PC-3U cells. We observed that nuclear accumulation of endogenous T $\beta R I-I C D$ decreased after siRNAmediated silencing of APPL1 and APPL2 (Figure 1D). In addition, knockdown of APPL1 and APPL2 led to less accumulation of a HA-tagged TRRI-ICD [13] in the nucleus (Figure S1A). That APPL1 promotes TGF $\beta$ induced translocation of T $\beta$ RI-ICD is further supported by the observation that transient overexpression of GFPAPPL1 enhanced the nuclear translocation of TRRIICD (Figure S1B). The amount of nuclear p-SMAD2 decreased slightly at 2-6 hours after TGF $\beta$ stimulation of APPL1- and APPL2-depleted cells (Figure 1D, 1E). Moreover, the level of p-p38 was increased in APPL1 and 

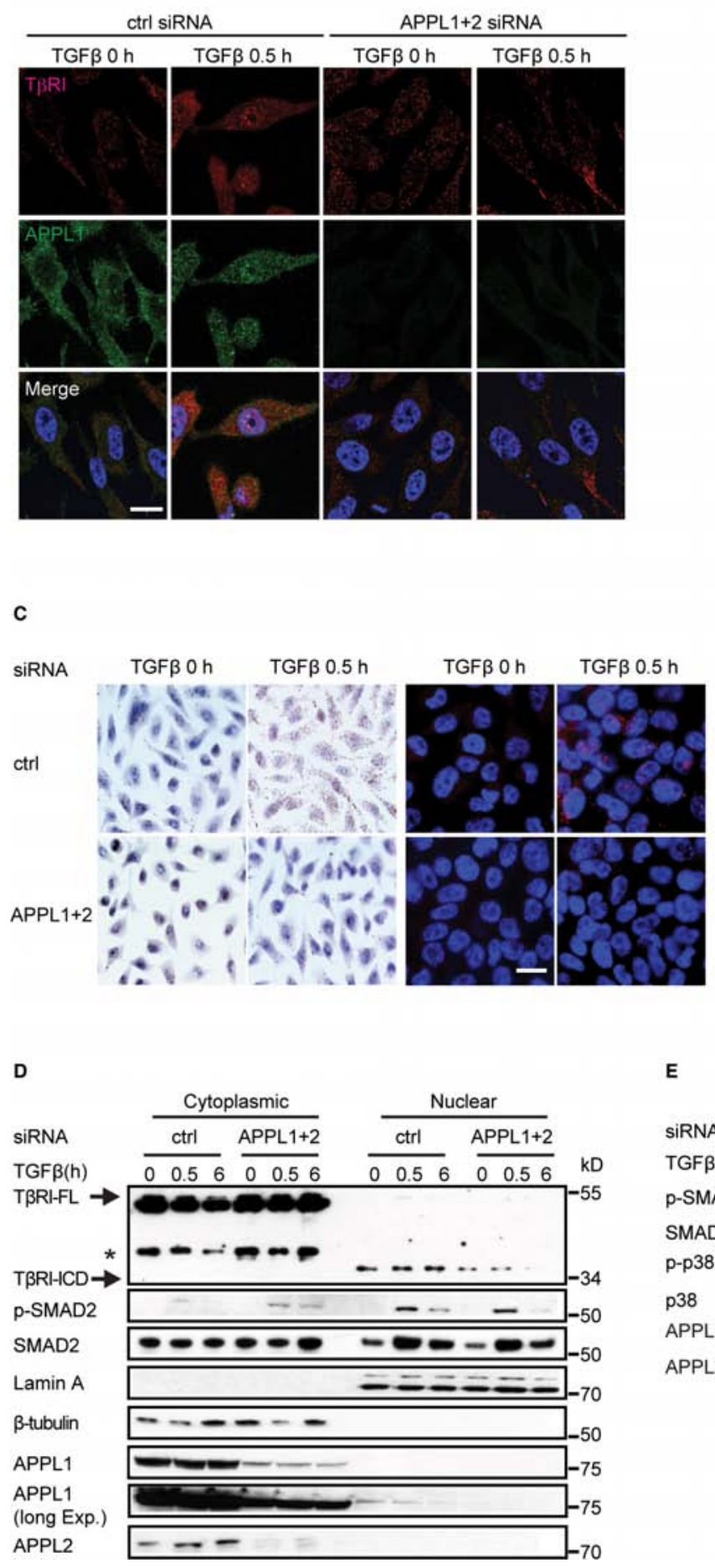

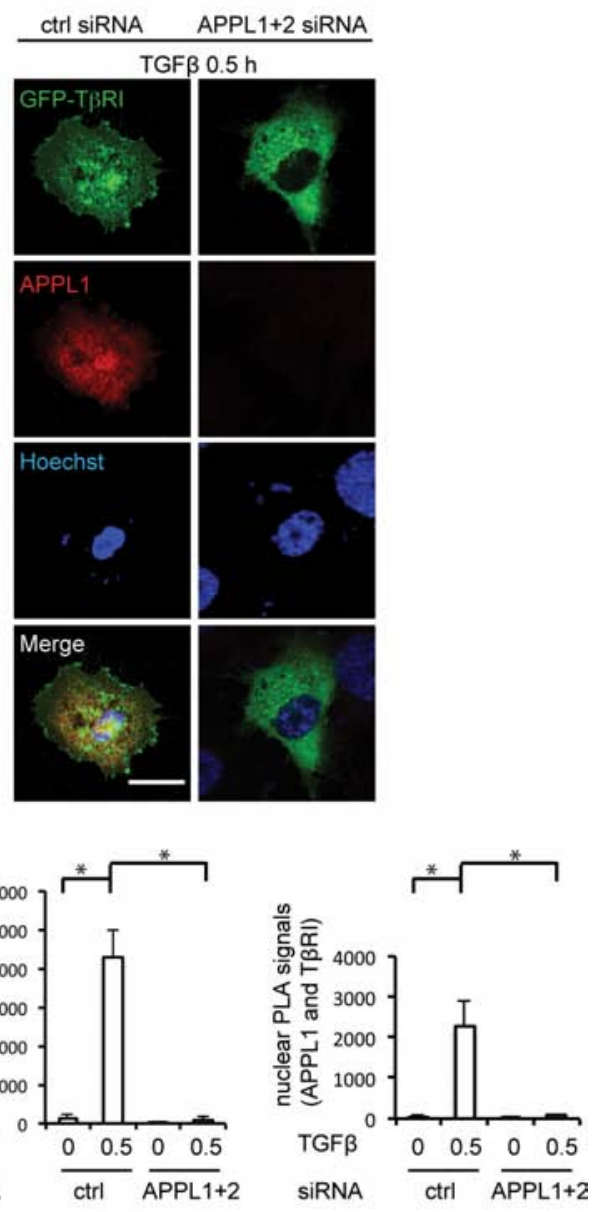

E

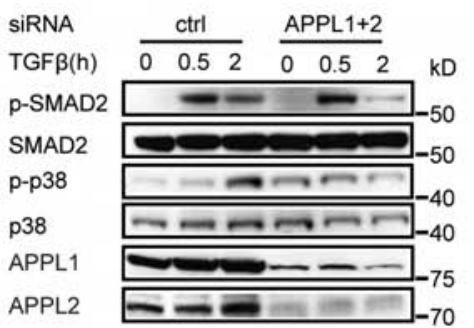

Figure 1: APPL proteins are involved in the nuclear translocation of T $\beta R I-I C D$ and in TGF $\beta$ signalling. (A) PC-3U cells in which APPL1 and APPL2 expression was, or was not, silenced using siRNA were treated with TGF $\beta$. APPL1 and T $\beta R I$ were visualized by immunofluorescence using APPL1 and V22 (FITC) antisera. Scale bar, $20 \mu \mathrm{m}$. (B) C-terminally GFP-tagged T $\beta$ RI was visualized in TGF $\beta$-stimulated cells treated, or not, with APPL1 and APPL2 siRNA. (C) PLA analysis (brightfield and immunofluorescence) of TGF $\beta$-induced formation of APPL1-T $\beta$ RI-ICD complex (brown and red, respectively). Quantification of total and nuclear PLA signals are shown in the right panel (mean \pm SD of three experiments; 350 cells were analyzed in each group). (D) Expression of APPL1 and APPL2 in PC-3U cells was knocked down using siRNA. The cells were subjected to cytoplasmic and nuclear protein fractionation; the lysates were analyzed by SDS-gel electrophoresis followed by immunoblotting for T $\beta$ RI-ICD and p-SMAD2. Lamin A and $\beta$-tubulin served as controls for the nuclear and cytoplasmic fractions, respectively. Asterisk marks a background band. (E) PC-3U cells in which APPL1 and APPL2 expression was or was not silenced by siRNA were treated with TGF $\beta$, or not, and subjected to immunoblotting for p-p38 and p-SMAD2. 
APPL2-silenced cells, but did not increase significantly in response to TGF $\beta$ stimulation (Figure 1E). These findings suggest that APPL proteins are implicated in TGF $\beta$ stimulated p38 MAPK and SMAD2 activation, as well as in the nuclear accumulation of T $\beta$ RI-ICD in PC-3U cells.

\section{APPL forms a complex with T $\beta R I$}

APPL endosomes have been found to be crucial for cargo trafficking and signal transduction downstream of various receptors including adiponectin receptors [32]. APPL endosomes are thought to be the precursors of classical EEA1-positive endosomes, and PI3P is important for their maturation [22]. We therefore investigated whether APPL1 forms a physical complex with T $\beta R I$. We performed co-immunoprecipitation experiments using lysates of PC-3U cells that were treated, or not, with TGF $\beta$. We observed that TGF $\beta$ treatment promoted an interaction between endogenous APPL1 and the full length T $\beta R I$ (Figure 2A, 2B). Notably, this interaction was enhanced when the cells were pretreated with the PI3K inhibitors LY294002 or wortmannin, which prevent the maturation of APPL-positive endosomes into EEA1-positive endosomes (Figure 2A, 2B). By contrast, treatment of cells with the T $\beta$ RI kinase inhibitor SB 505124 had no

A

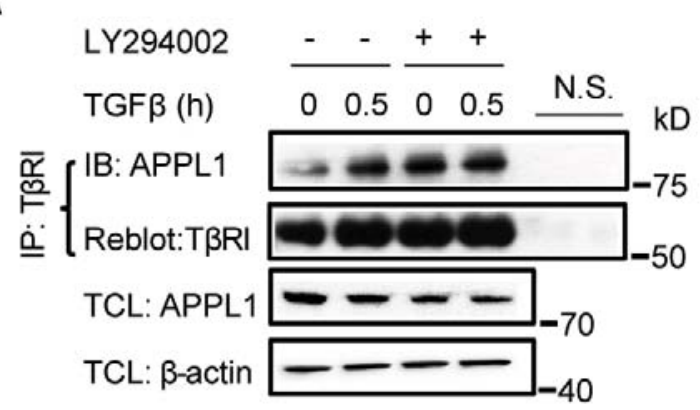

C

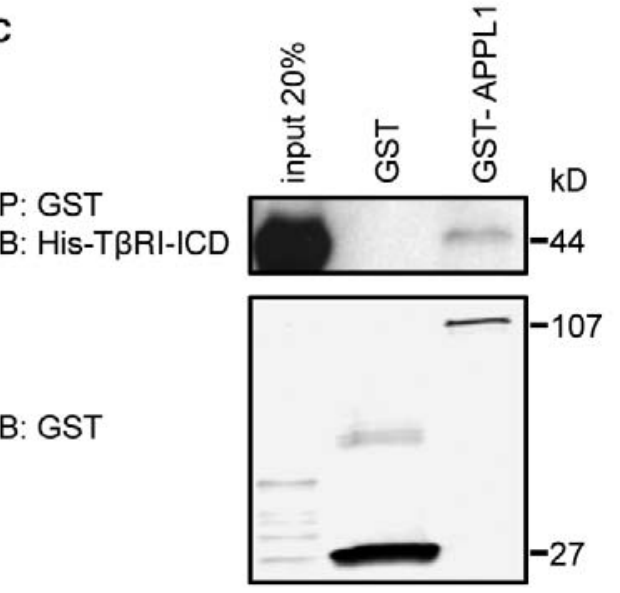

effect on the interaction of APPL1 and T $\beta$ RI (Figure S1C). Moreover, His-tagged T $\beta$ RI-ICD and HA-T $\beta$ RI bound to recombinant GST-tagged APPL1 (Figure 2C, 2D), confirming the results shown in Figure 2A, 2B, that endogenous proteins interacted.

To elucidate which part of APPL1 mediates binding to T $\beta R I$, we performed co-immunoprecipitation and immunofluorescence experiments with various APPL fragments. Transient expression of HA-T $\beta$ RI together with two different GFP-APPL truncation mutants in PC-3U cells revealed that the C-terminus, but not the $\mathrm{N}$-terminus, of APPL1 bound to T $\beta$ RI (Figure S1D, S1E). We conclude that TGF $\beta$ promotes the association of T $\beta \mathrm{RI}$ and APPL1, consistent with the possibility that at least a portion of T $\beta$ RI is found in APPL1-positive endosomes.

\section{TRAF6 is required for TßRI-APPL complex formation}

The subcellular localization of proteins can be modulated by post-translational modifications, such as phosphorylation and Lys63-linked polyubiquitination [34]. We have previously shown that the E3 ubiquitin ligase TRAF6 is required for the Lys63-linked polyubiquitination of T $\beta$ RI and the subsequent formation of the T $\beta$ RI-ICD

B
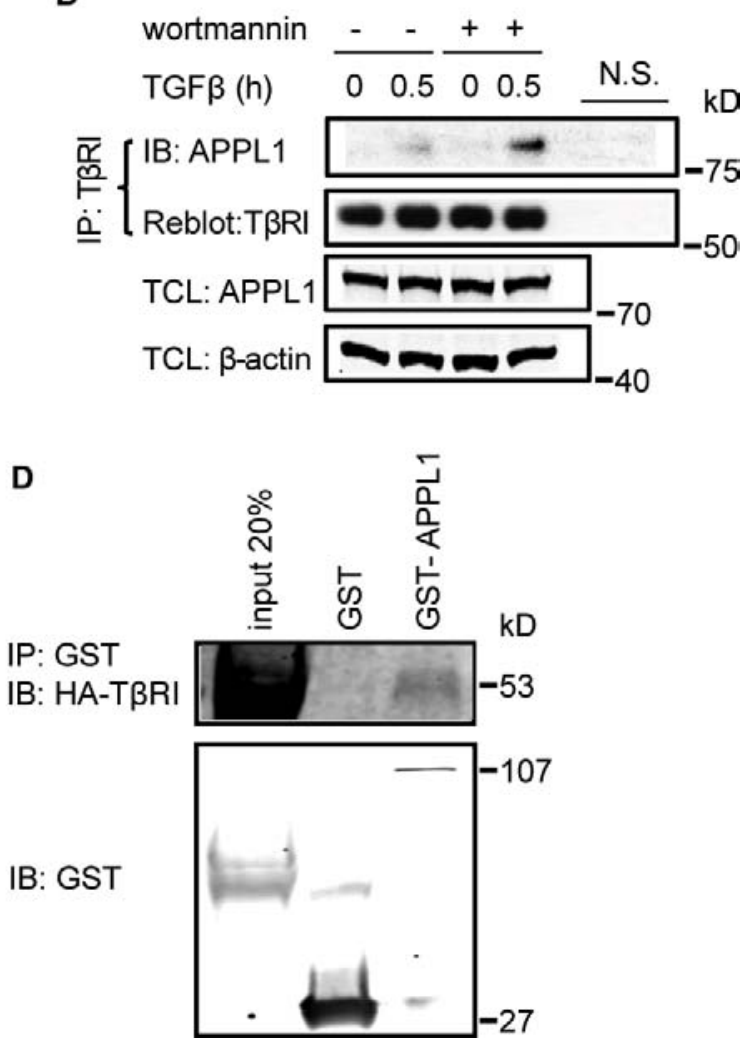

Figure 2: APPL1 associates with T $\beta$ RI. (A), (B) Inhibition of the activity of PI3 kinase enhanced the association between endogenous T $\beta R I$ and APPL1. Cell lysates from PC-3U cells treated or not with TGF $\beta$ and the PI3 kinase inhibitors LY294002 or wortmannin, were immunoprecipitated with an antibody against TRRI (V22) and subjected to immunoblotting with an APPL1 antibody. N.S., non-specific control, including beads control and IgG control. (C), (D) In vitro interaction of GST-APPL1 proteins, with His-T $\beta$ RI-ICD and HA-T $\beta R I$. 
in response to stimulation with $\mathrm{TGF} \beta$, in a manner dependent on $\mathrm{PKC} \zeta[10]$. We therefore investigated the role of TRAF6 in TGF $\beta$-induced endosomal sorting of T $\beta$ RI to APPL1-positive endosomes. PLA analysis using antisera against Lys63-linked polyubiquitin and APPL1 suggested that APPL1 is subjected to Lys63-linked polyubiquitination (Figure 3A). Moreover, T $\beta$ RI was sorted to APPL1-positive endosomes in control cells, but not in cells depleted of TRAF6 by siRNA (Figure 3B). As we have previously shown that TRAF6 and PKC $\zeta$ are important for proteolytic cleavage of T $\beta R I$, we investigated whether APPL1 interacts with PKC $\zeta$. A TGF $\beta$-induced association of APPL1 with $\mathrm{PKC} \zeta$ was demonstrated by PLA analysis (Figure 3C); this interaction was not seen after knockdown of TRAF6 by siRNA, as analyzed by coimmunoprecipitation (Figure 3D). PKC $\zeta$ pseudosubstrate or T $\beta R I$ kinase inhibitors had no effect on the association between APPL1 and PKC $\zeta$ (Figure S2A, S2B). These observations suggest that TRAF6 promotes the sorting of T $\beta$ RI to APPL1-positive endosomes.

\section{A}
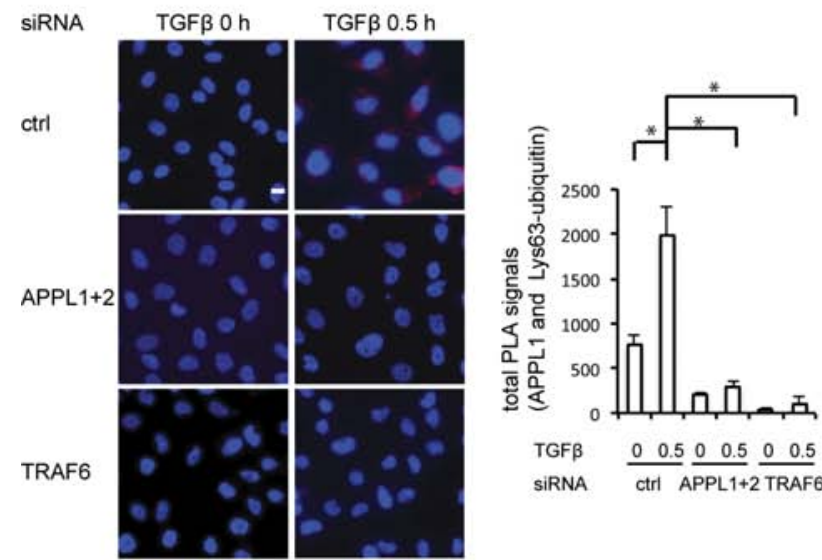

C

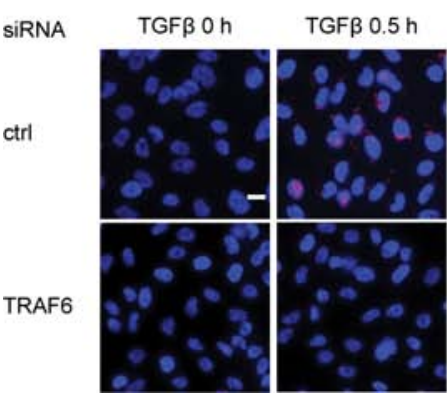

\section{APPL proteins are involved in the trafficking of T $\beta$ RI-ICD to the nucleus}

To further verify the role of APPL proteins in trafficking of T $\beta R I$, we transiently co-transfected GFPtagged APPL1 and C-terminally HA-tagged T $\beta R I$ in PC-3U cells, and examined the subcellular localization of these proteins using confocal imaging. We observed that GFP-APPL1 and HA-T $\beta$ RI co-localized in the nucleus in response to TGF $\beta$, whereas the nuclear translocation of the proteins was prevented in cells treated with the PI3K inhibitor wortmannin (Figure 4A). Co-immunoprecipitation revealed that endogenous APPL1 associated with T $\beta$ RI-ICD in nuclear fractions derived from PC-3U cells in a TGF $\beta$-dependent manner; however, treatment with wortmannin inhibited the formation of a nuclear complex of APPL1 and T $\beta$ RI (Figure 4B). In addition to the co-localization with APPL-positive endosomes in the cytosol (Figure 4A), T $\beta$ RI was also localized in Rab5-positive endosomes (Figure 4C). TGF $\beta$
B

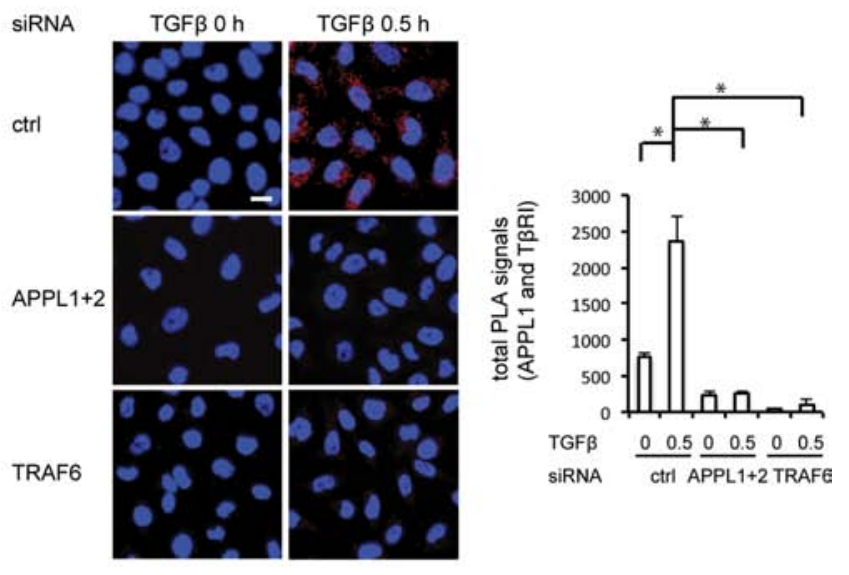

D

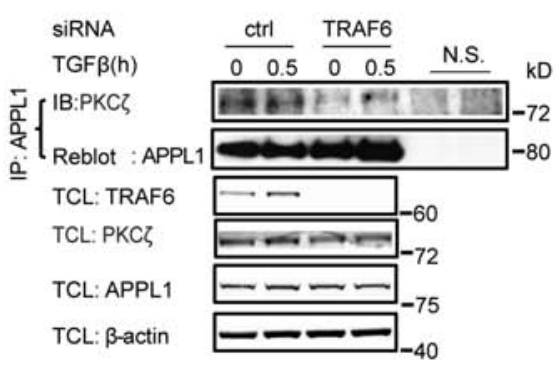

Figure 3: TRAF6 promotes the formation of the T及RI-APPL1 complex. (A) Representative images showing the association between APPL1 and Lys63-polyubiquitin (red), determined by PLA in PC-3U cells in which TRAF6 or APPL proteins were knocked down, or not, in the presence or absence of TGF $\beta$. (B) Association between APPL1 and T $\beta R I$ (red), determined by PLA in PC-3U cells in which TRAF6 or APPL proteins were knocked down, or not. (C) PLA was used to determine the formation of a complex between APPL1 and PKC $\zeta$ in PC-3U cells in which TRAF6 proteins were silenced, or not. Quantifications of total and nuclear PLA signals in the right panel show the means \pm SD of three experiments; 350 cells were analyzed in each group (in Figure 3A-3C). (D) Silencing the expression of TRAF6 decreased the association between endogenous PKC $\zeta$ and APPL1. Cell lysates from PC-3U cells treated as indicated were immunoprecipitated with an antibody against APPL1 and subjected to immunoblotting with a PKC $\zeta$ antibody. 
A
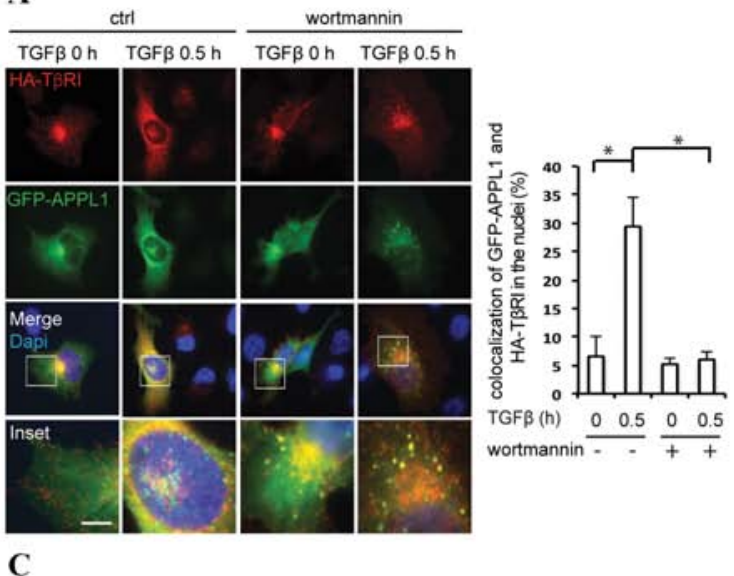

B

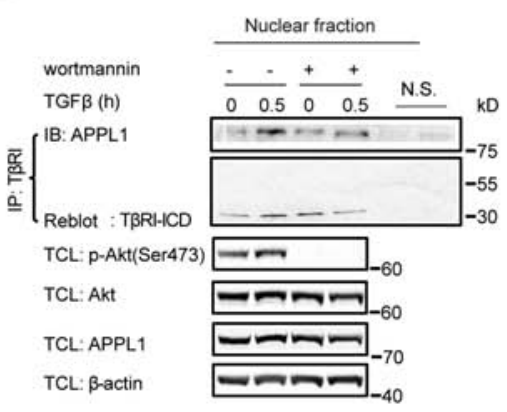

C

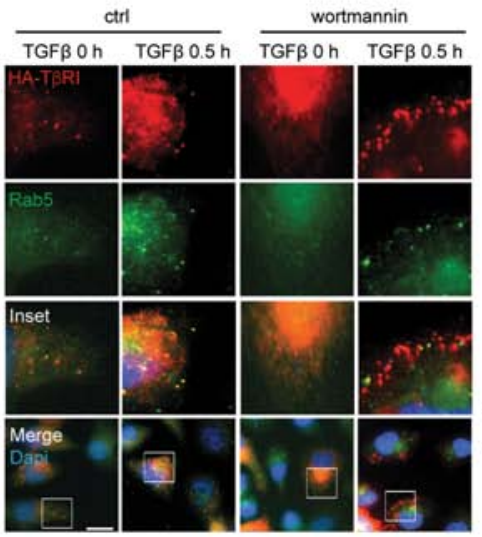

D

$\mathbf{E}$

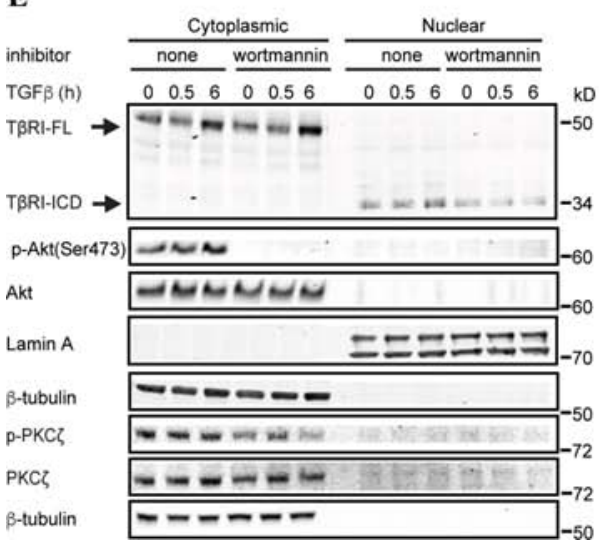

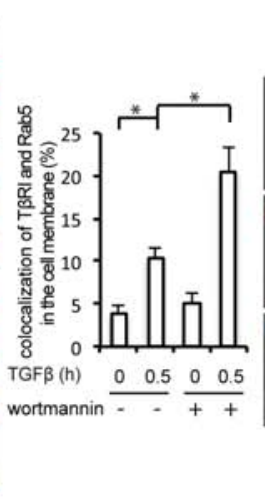

$\mathbf{F}$
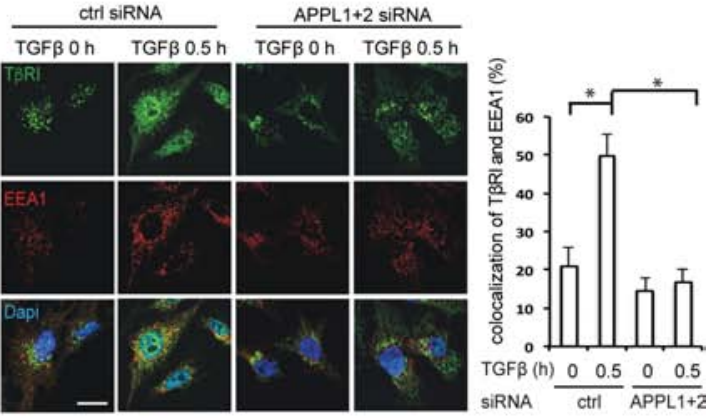

Figure 4: APPL proteins are necessary for trafficking of T $\beta R I-I C D$ from the cell membrane to the nucleus. (A) PC-3U cells transiently transfected with GFP-APPL1 and C-terminally tagged HA-T $\beta$ RI were treated, or not, with TGF $\beta$ and wortmannin. Protein co-localization is shown as yellow dots in the merged images. Bar graph shows the percentage of GFP-APPL1 and HA-T $\beta$ RI complex in the nuclei, based on 300 cells counted in each group. Scale bar, $20 \mu \mathrm{m}$. (B) The PC-3U cells were treated with wortmannin as indicated and then subjected to cytoplasmic and nuclear protein fractionation, and the nuclear lysates were immunoprecipitated with T $\beta R I$ antibody (V22) followed by immunoblotting with APPL1 antibody. (C) PC-3U cells transiently transfected with HA-T $\beta$ RI were untreated or treated with TGF $\beta$ and wortmannin and then stained with HA and Rab5 antibodies. Bar graph shows the percentage of T $\beta$ RI-Rab5 complex in the cell membrane, based on 300 cells counted in each group. Scale bar, $20 \mu \mathrm{m}$. (D) Confocal immunofluorescence analysis of EEA1 and T $\beta R I$ was performed in PC-3U cells in which APPL1 and APPL2 expression was, or was not, silenced by siRNA. Scale bar, $20 \mu \mathrm{m}$. Bar graph shows the percentage of T $\beta R I-E E A 1$ complex in PC-3U cells, based on 300 cells counted in each group. Scale bar, $20 \mu \mathrm{m}$. (E) PC-3U cells, which were treated with wortmannin, were subjected to cytoplasmic and nuclear protein fractionation, and the lysates were subjected to SDS-gel electrophoresis, followed by immunoblotting to detect T $\beta$ RI-ICD, Akt and PKC $\zeta$. Lamin A and $\beta$-tubulin were used as markers for the nuclear and cytoplasmic fractions, respectively. A representative experiment of three independent experiments is shown. (F) APPL1 associates with $\beta$-tubulin in a TRAF6-dependent manner. Cell lysates from PC-3U cells transiently transfected with control or TRAF6 siRNA were immunoprecipitated with an antibody against APPL1 and subjected to immunoblotting with a $\beta$-tubulin antibody. 
treatment induced the localization of T $\beta R I$ in Rab5-positive endosomes; however, most T $\beta \mathrm{RI}$ remained close to the plasma membrane when the PC-3U cells were pretreated with wortmannin (Figure 4C). Furthermore, T $\beta$ RI was detected in EEA1-positive endosomes after TGF $\beta$ treatment for 30 minutes, whereas significantly less T $\beta$ RI was present in EEA1-positive endosomes after knockdown of APPL1 and APPL2 (Figure 4D). The amount of nuclear T $\beta$ RI-ICD that could be detected by immunoblotting decreased after pretreatment of cells with wortmannin (Figure 4E), in line with data shown in Figure 4B. Many proteins are transported along microtubules, therefore, we investigated whether APPL1 associates with $\beta$-tubulin using co-immunoprecipitation. As shown in Figure 4F, we found that APPL1 associates with microtubules and that this interaction is promoted by TRAF6. Taken together, these observations suggest that APPL proteins are involved in trafficking of the T $\beta$ RI-ICD from the endosomes to the nucleus via microtubules in a TRAF6-dependent manner, and that APPL1 maturation, shedding and nuclear accumulation are controlled by different phosphoinositides, consistent with previous observations [22], [27].

\section{A}
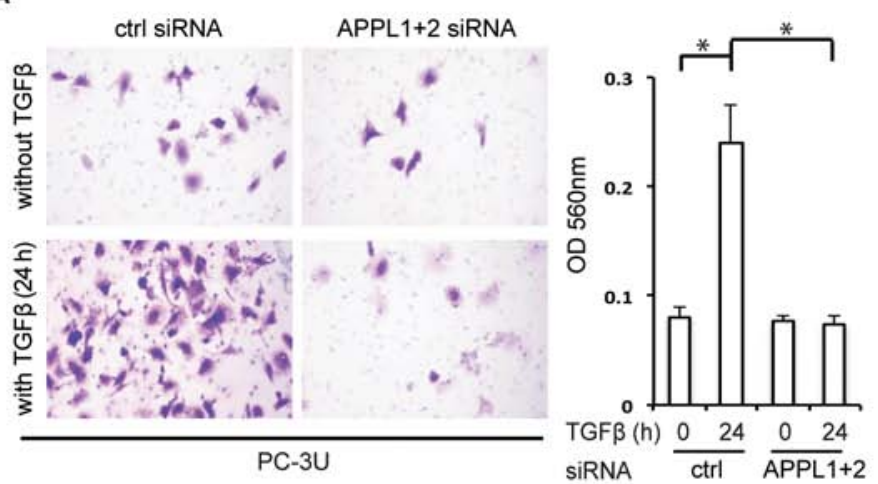

C
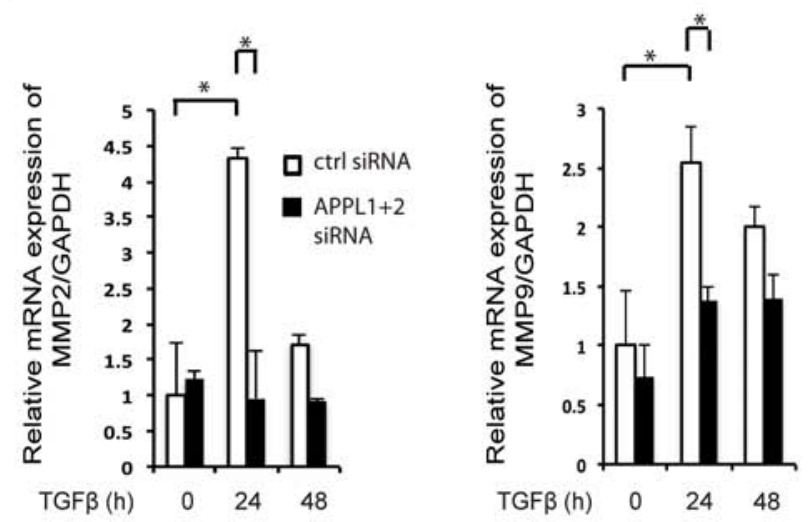

D

\section{APPL proteins promote nuclear TRRI-ICD- induced cancer invasion}

Nuclear T $\beta$ RI-ICD has been found to promote the invasion of various cancer cells $[12,13]$ and as APPL proteins was found to be crucial for its nuclear translocation, we investigated the role of APPL1 and APPL2 in TGF $\beta$-induced invasiveness in cancer cells. Using a two-layer chamber, we observed TGF $\beta$-induced invasion by the human prostate cancer PC-3U cells (Figure 5A) and breast carcinoma MDA-MB-231 cells (Figure 5B), in line with our previous reports [12, 13]. By contrast, silencing of APPL1 and APPL2 resulted in a decrease in TGF $\beta$-induced invasion of by both these cell lines. Quantitative real-time polymerase chain reaction (qRT-PCR) analysis showed that transcription of the cancer-associated matrix metalloprotease 2 (MMP2) and MMP9 decreased after silencing of APPL1 and APPL2 (Figure 5C). Treatment of PC-3U cells with $1 \mu \mathrm{M}$ of the MMP2 and MMP9 inhibitor SB-3CT inhibited invasion in response to TGF $\beta$ stimulation of cells (Figure 5D). These findings support the notion that APPL-promoted nuclear
B
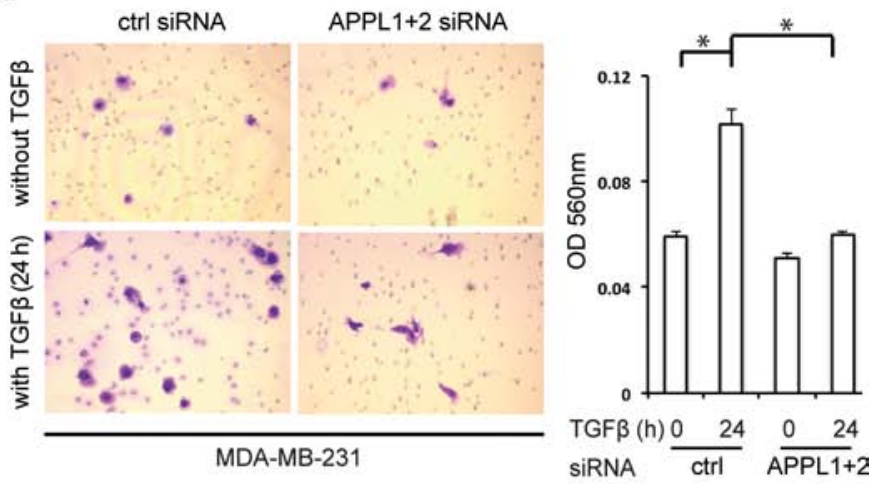
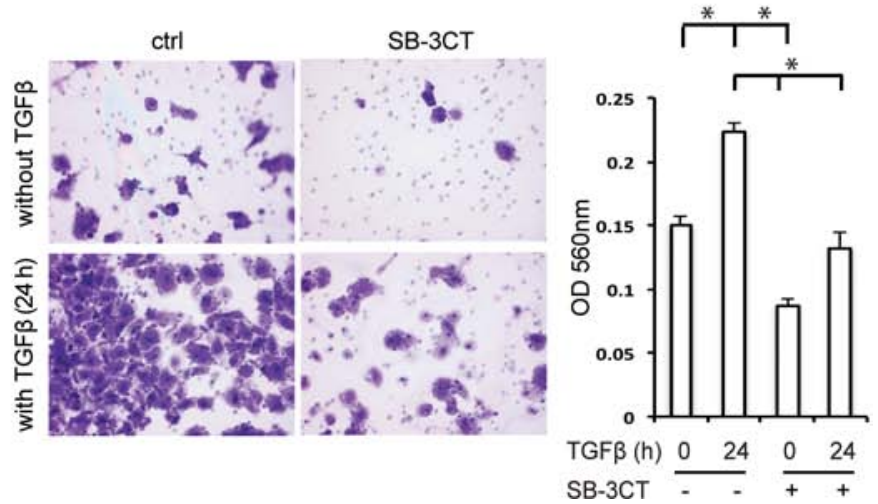

Figure 5: Knockdown of APPL proteins reduces TßRI-ICD-mediated cell invasion. (A), (B) Invasion assays using PC-3U cells (A) and MDA-MB-231 cells (B) treated, or not, with APPL1 and APPL2 siRNA and with TGF $\beta$. Cells were visualized by crystal violet cell staining; the panels represent the mean optical density (OD) values of invasive cells (mean $\pm \mathrm{SD},{ }^{*} P<0.05$; Mann-Whitney $U$ test). (C) qRT-PCR analysis for expression of MMP2 and MMP9 genes was performed on mRNA extracted from PC-3U cells which had been treated with APPL1 and APPL2 siRNA and stimulated with TGF $\beta$, as indicated. (D) Invasion assay using PC-3U cells that were untreated or treated with $1 \mu \mathrm{M}$ SB-3CT and/or TGF $\beta$ (mean $\pm \mathrm{SD},{ }^{*} P<0.05$; Mann-Whitney $U$ test). 
translocation of T $\beta$ RI-ICD leads to increased expression of proteins involved in invasion, such as MMP2 and MMP9.

\section{APPL1 expression is higher in malignant prostate tissue than in normal prostate tissue}

To further elucidate the role of APPL1 in cancer, we examined the expression and localization of APPL1 in normal and malignant prostate tissue by immunohistochemistry, as aberrant endocytosis of growth factor receptors has been found to be occur during cancer initiation and progression [35, 36]. In normal prostate tissue, APPL1 was expressed only in basal epithelial cells but not in luminal cells, whereas in malignant prostate tissues APPL1 was expressed in all cancer cells (Figure 6A-6C). APPL1 was also expressed in all epithelial cells in high-grade prostate intraepithelial neoplasia (HGPIN), suggesting that APPL1 participates in prostate cancer progression (Figure 6A). We also found that APPL1 staining, both in the cytoplasm and the nucleus, positively correlated with higher Gleason Score which is correlated to more aggressive disease (Table 1).

As we observed that APPL1 promotes the transport of T $\beta$ RI-ICD to the nucleus of prostate cancer cells and
A
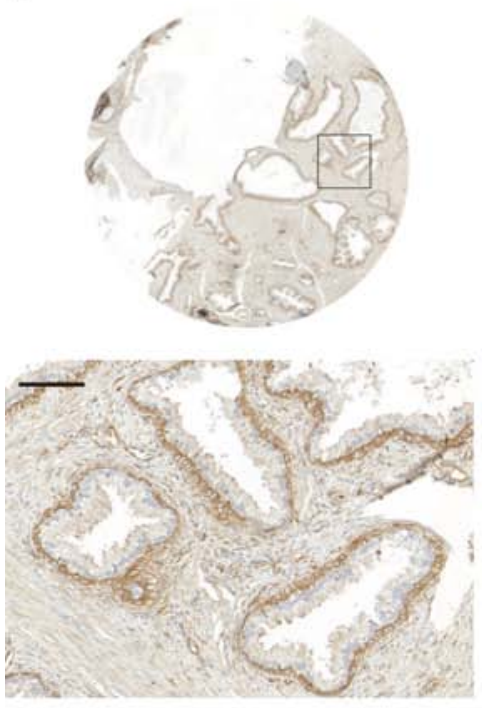

normal prostate/high grade PIN
B
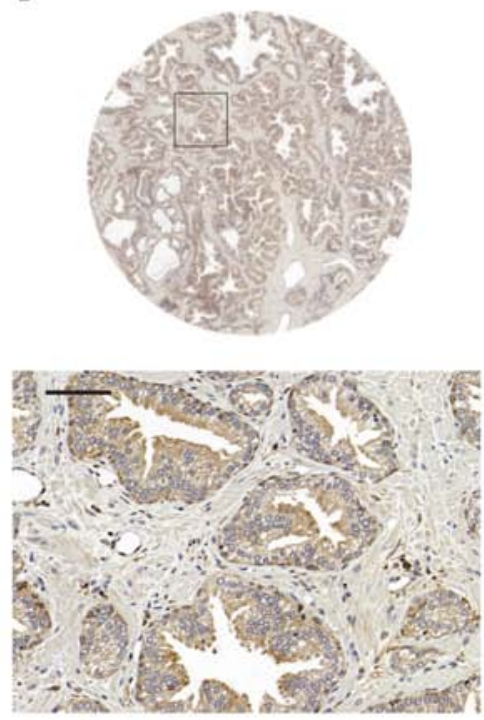

prostate cancer

Gleason 6
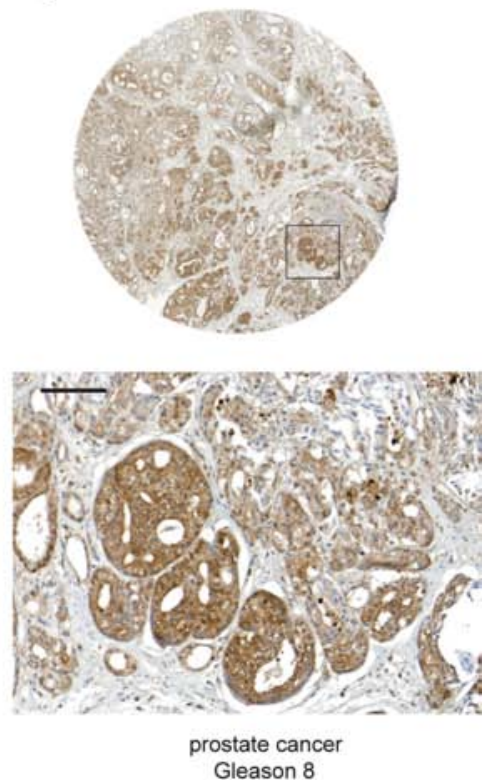

D
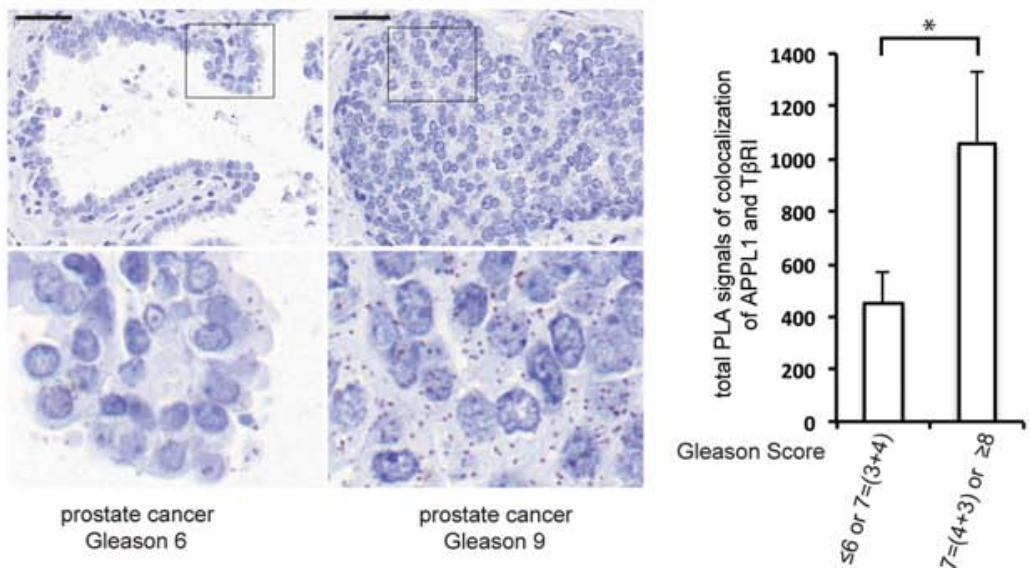

Figure 6: The expression of APPL1 differs in normal versus malignant prostate tissue. (A)-(C) Normal prostate tissue and prostate tumour tissue samples were stained with APPL1 antibodies. Scale bar, $100 \mu \mathrm{m}$. (D) The association between APPL1 and T $\beta R I$ in prostate cancer patients (brown dots) was determined by PLA; 350 cells were analyzed in each sample. Quantification shows the means \pm SD of ten patients in each group. ${ }^{*} P<0.05$; Mann-Whitney $U$ test. Scale bar, $50 \mu \mathrm{m}$. 
Table 1: Clinicopathologic features and APPL1 expression

\begin{tabular}{|c|c|c|c|c|c|}
\hline \multirow[b]{2}{*}{ Gleason score } & \multicolumn{3}{|c|}{ Cytoplasmic staining } & \multicolumn{2}{|c|}{ Nuclear staining } \\
\hline & No. ${ }^{\mathrm{a}}$ & mean $^{b}$ & SE & mean $^{c}$ & SE \\
\hline$\leq 6$ or $7=(3+4)$ & 32 & 2.91 & 0.296 & 0.84 & 0.448 \\
\hline $7=(4+3)$ or $\geq 8$ & 26 & 4.42 & 0.578 & 2.08 & 0.484 \\
\hline
\end{tabular}

anumber of patients

${ }^{\mathrm{b} C y t o p l a s m i c ~ m e a n ~ s t a i n i n g ~ s c o r e ; ~ d i f f e r e n c e ~ b e t w e e n ~ g r o u p s, ~} P<0.001$; Mann-Whitney $U$ test

'Nuclear mean staining score; difference between groups, $P<0.001$.

that this is connected to invasiveness [12], we investigated whether the APPL1-T $\beta R I-I C D$ complex could be found in prostate cancer tissues. Using PLA, we detected a significantly higher number of APPL1-TßRI complexes in sections from patients with aggressive prostate cancer compared with less aggressive tumours (Figure 6D).

\section{DISCUSSION}

In this study, we have identified a role for APPL1 and APPL2 proteins in the trafficking of TRRI-ICD to the nucleus. APPL1 interacts with TRRI in a TRAF6 dependent manner and the interaction is mediated by its $\mathrm{C}$-terminus. The resulting protein complex localizes to a subpopulation of early endosomes that is important for the nuclear translocation of T $\beta R I-I C D$. We also found that the TGF $\beta$-induced invasion of cancer cells is dependent on APPL1 and APPL2 expression and that the APPL1 expression is increased in malignant prostate cancer tissues compared with normal prostate tissues. Interestingly, we also observed a greater number of APPL1-T $\beta R I$ complexes in more aggressive prostate cancer tissues. Taken together, these observations suggest that the endosomal proteins APPL1 and APPL2 are important for the nuclear trafficking of T $\beta$ RI-ICD, which is regulated by TRAF6 and is linked to prostate cancer progression.

APPL proteins are multifunctional adaptors proteins which associate with signalling molecules, such as PI3K, to facilitate endocytosis of various receptors [21, 22]. In this way, the APPL proteins may provide platforms for directing downstream signalling pathways. Moreover, both APPL1 and APPL2 translocate into the nucleus from the cytosol in response to EGF stimulation, to regulate cell proliferation $[23,37]$. Our finding that APPL proteins interact with TRRI-ICD to promote its intracellular trafficking now expands the roles of APPL proteins to TGF $\beta$ signalling.

Nuclear T $\beta$ RI-ICD, which has been observed in cancer cells both in vivo and in vitro [12], associates with the transcriptional co-regulator p300 to activate genes involved in cancer cell invasion [12]. The functional importance of nuclear T $\beta$ RI-ICD is supported here by the finding that TGF $\beta$-induced cancer cell invasion was suppressed after knockdown of APPL1 and APPL2
(Figure 5). APPL1 and APPL2 have been linked to cell survival in vertebrate development and in human glioma cells $[38,39]$. $\mathrm{APPL}^{-/}$cells showed a reduced migration capacity, and knockdown of APPL2 further decreased the mobility of APPL1 $1^{-/}$cells [40]. In tissues from prostate cancer, APPL1 expression was found to correlate with tumour malignancy (Gleason Score), indicating an important functional role for APPL1 in tumourigenesis of prostate cancer (Figure 6). Interestingly, the immunohistochemical localization of the APPL1 protein differed in healthy prostate tissue and malignant prostate tissue (Figure 6). Increased levels of APPL proteins in prostate cancer was also recently described by another group (41). It has been shown that T $\beta$ RI-ICD associates with p300 and activates genes involved with tumour invasion, such as MMP2 [12, 42]; here, we show by knockdown of APPL proteins that the nuclear T $\beta R I-$ ICD-APPL protein complex regulates MMP2 and MMP9 expression, which could promote cancer cell invasion (Figure 5C, 5D).

The precise mechanism whereby the APPL1-T $\beta R I-$ ICD complex enters the nucleus needs to be further explored, as APPL1 does not contain any obvious nuclear localization signal. A possible nuclear localization signal in APPL2 has recently been observed in silico [43], but its functional role has not been tested experimentally. It is known that APPL1 dissociates from early endosomes when APPL1 endosomes mature [22] and that APPL1 accumulates in the nucleus in response to EGF [23], although the molecular mechanisms behind this nuclear translocation event remain to be elucidated. TRRI-ICD formation and nuclear transport have been shown to be dependent on TRAF6, importin $\beta 1$ and nucleolin $[44,45]$. In this study, we found that TGF $\beta$ induces PI3Kdependent maturation of endosomes and Lys63-linked polyubiquitination of APPL1 in a TRAF6-dependent manner, promoting the nuclear translocation of APPL1 and TRRI-ICD. Future studies aiming at elucidating the detailed mechanisms for nuclear translocation of the APPL1-TßRI-ICD complex and their nuclear transcriptional targets besides MMP2 and MMP9, are warranted, to better understand the protumorigenic effects of TGF $\beta$.

In conclusion, our study has identified APPL-positive endosomes as a transient early endocytotic compartment 
that is crucial for trafficking of T $\beta$ RI-ICD. We observed that nuclear translocation of the APPL1-TGF $\beta$ RI-ICD complex correlated with an increased expression of the MMP2 and MMP9 genes. Moreover, a greater number of APPL1-T $\beta R I-I C D$ complexes were detected in sections from aggressive human prostate cancer tissues compared with less aggressive tumours, suggesting that increased expression of APPL1 could provoke alternative TGF $\beta$ signalling routes resulting in cancer progression. Future studies in larger clinical materials will be important to evaluate the clinical value of the herein reported APPL1T $\beta$ RI-ICD complex as a potential prognostic marker in tissues from patients with cancer.

\section{MATERIALS AND METHODS}

\section{Ethics statement}

The investigation has been conducted in accordance with the ethical standards and according to the Declaration of Helsinki and according to national and international guidelines and has been approved by the authors' institutional review board.

\section{Cell culture}

The PC-3U human prostatic carcinoma cell line represents a clone from the original PC-3 cell line (ATCC CRL-1435). The PC-3U cells was grown in RPMI-1640 with $10 \%$ fetal bovine serum (FBS) and $2 \mathrm{mM}$ L-glutamine [46]. The human breast cancer cell line MDA-MB-231 used in this study was purchased from ATCC (ATCC CRMHTB-26), and cells were grown in L15 media with $15 \%$ FBS and $2 \mathrm{mM}$ L-glutamine. For TGF $\beta$ stimulation, TGF $\beta$ $(5 \mathrm{ng} / \mathrm{ml})$ was added in medium containing $1 \% \mathrm{FBS}$ to cells that had been starved for 12-18 h.

\section{Antibodies and reagents}

The following antibodies were used for immunoblotting, immunoprecipitation (IP), or immunofluorescence (IF). Antibodies against APPL1 (dilution 1:1, 000), Lamin A (1:1, 000), p-PKC $\zeta / \lambda$ (Thr410/403, 1:1, 000), p-p38 (1:1, 000), p38 $(1: 1,000)$ and $\operatorname{SMAD} 2(1: 1,000)$ were purchased from Cell Signaling; p-SMAD2 (1:500) was generated in rabbits in-house; APPL2 (1:500), T $\beta$ RI (V22, 1:500) were purchased from Santa Cruz Biotechnology. The V22 antibody recognizes nuclear T $\beta$ RI-ICD and its specificity was reported previously [12]; antibodies against HA (2 $\mu \mathrm{g}$ for IP), and $\beta$-actin and $\beta$-tubulin were from Roche and Sigma, respectively. APPL1 antibody for the PLA experiments was purchased from Santa Cruz Biotechnology, whereas Alexafluor 555 and 488 were from Invitrogen, and Lys63 polyubiquitin antibody from Enzo Life Science. Horseradish peroxidase-coupled secondary antibodies were purchased from Sigma, and the secondary antibody for Odyssey Clx machine was purchased from Licor Biosciences. Protein-G Sepharose and ECL Western blotting detection reagents were from GE Healthcare. Pefabloc was from Roche, and the PageRuler Prestained Protein Ladder was from Fermentas. The PI3 kinase inhibitor LY294002 $(10 \mu \mathrm{M})$ was purchased from Calbiochem and wortmannin $(100 \mathrm{nM})$ was from Sigma. The MMP2 and MMP9 inhibitor SB-3CT was purchased from Santa Cruz Biotechnology. The inhibitors were added $1 \mathrm{~h}$ before TGF $\beta$ stimulation, with exception of the experiment in Figure 4B, in which the cells were treated with wortmannin for $6 \mathrm{~h}$ before TGF $\beta$ stimulation.

\section{Protein analysis}

For the TGF $\beta$ stimulation experiments, cells were starved for $12-18 \mathrm{~h}$ and then treated with TGF $\beta$ for the indicated time periods. Cells were washed twice with ice-cold phosphate-buffered saline (PBS) and lysed in ice-cold lysis buffer $(150 \mathrm{mM} \mathrm{NaCl}, 50 \mathrm{mM}$ Tris $\mathrm{pH}$ $8.0,0.5 \%$ (v/v) DOC, $1 \%$ (v/v) NP-40, 10\% (v/v) glycerol, $1 \mathrm{mM}$ aprotinin, $1 \mathrm{mM}$ Pefabloc and $2 \mathrm{mM}$ sodium orthovanadate). After centrifugation, the supernatants were collected and the protein concentrations were measured using the BCA Protein Assay Kit (Thermo Scientific). Equal amounts of protein from each total cell lysate were subjected to immunoprecipitation. Immunoprecipitated proteins were resolved by SDS-PAGE using 7\% or $10 \%$ Bis-Tris Precast gels (Life Technologies), MiniPROTEAN TGX gels and Criterion TGX Precast gels (Bio-Rad), blotted onto nitrocellulose membranes, and subjected to immunoblotting as described previously [47].

\section{Nuclear fractionation assay}

After starvation and stimulation with TGF $\beta 1$, PC-3U cells were washed twice with ice-cold PBS, and scraped in ice-cold PBS. After centrifugation for $5 \mathrm{~min}$ at 2000 rpm at $4^{\circ} \mathrm{C}$ the supernatant was discarded. The pellets were treated with ice-cold lysis buffer containing $10 \mathrm{mM}$ morpholine ethanesulfonic acid (MES; pH 6.2), $10 \mathrm{mM}$ $\mathrm{NaCl}, 1.5 \mathrm{mM} \mathrm{MgCl}, 1 \mathrm{mM}$ EDTA, $5 \mathrm{mM}$ dithiothreitol (DTT), 1\% Triton X-100, and protease inhibitors. After a second centrifugation step the supernatant containing the cytoplasmic part was removed. The remaining nuclear pellet was washed three times with ice-cold washing buffer (same as lysis buffer but without Triton X-100), and then dissolved in an ice-cold extraction buffer (25 mM Tris-HCl, pH 10.5, $1 \mathrm{mM}$ EDTA, 0.5 M NaCl, $5 \mathrm{mM} \beta$-mercaptoethanol, $0.5 \%$ Triton X-100). Both the cytoplasmic and nuclear fractions were then centrifuged at $13,000 \mathrm{rpm}$ [48].

\section{Immunofluorescence and microscope image acquisition}

Immunofluorescence assays were performed as described previously [12, 47, 48]. In brief, cells were 
plated on coverslips and fixed in 4\% paraformaldehyde for $30 \mathrm{~min}$, treated with $0.2 \%$ Triton $\mathrm{X}-100$ in PBS for $5 \mathrm{~min}$ at room temperature and then blocked with $10 \mathrm{mM}$ glycine. Incubation with the primary antibodies was performed for $1 \mathrm{~h}$ at room temperature, followed by washing in PBS and then incubation with the secondary antibodies. Photomicrographs were obtained using a confocal microscope LSM 710 (Carl Zeiss) using a $63 \times 1.4 /$ NA objective lens (Carl Zeiss). The images were acquired using the Zen 2010 software in the presence of immersion oil at room temperature.

\section{In situ proximity ligation assay (PLA)}

PC-3U cells were treated, or not, with TGF $\beta$ for $30 \mathrm{~min}$, fixed in $4 \%$ paraformaldehyde and permeabilized in $0.2 \%$ Triton X-100. For brightfield PLA analysis, the tissue sections were pretreated with deparaffinization, retrieval and permeabilization. In situ proximity ligation assay was performed according to the manufacturer's instructions with the Duolink Detection Kit (Sigma). Photomicrographs for immunofluorescence were taken with an AX10 microscope (Carl Zeiss) using a $40 \times 0.95 /$ NA objective lens (Carl Zeiss). The images were acquired with Zen 2 pro software at room temperature. The camera was a Hamamatsu Digital Camera C11440. Images for brightfield were acquired with Pannoramic 250 Flash.

\section{In vitro binding assays}

Purified GST-tagged APPL1 (Abnova) or recombinant GST, as a control, were immobilized on the glutathione Sepharose beads (GE Healthcare) in buffer 1 (20 mM Tris-HCl, pH 7.9, 20\% glycerol, $1 \mathrm{mM}$ EDTA, $5 \mathrm{mM} \mathrm{MgCl}_{2}$, 0.1\% NP-40, 1 mM DTT, $0.2 \mathrm{mM}$ phenylmethylsulphonyl fluoride (PMSF), $0.1 \mathrm{M} \mathrm{NaCl}$ ), at $4^{\circ} \mathrm{C}$ overnight. The beads were washed three times with buffer 1, and one time in Buffer $2(20 \mathrm{mM}$ Tris- $\mathrm{HCl}$, pH 7.9, 20\% glycerol, $5 \mathrm{mM} \mathrm{MgCl}_{2}, 5 \mathrm{mM} \mathrm{GaCl}_{2}, 0.1 \%$ NP-40, $1 \mathrm{mM}$ DTT, $0.2 \mathrm{mM}$ PMSF, 0.1 M NaCl), then incubated with purified His-tagged T $\beta$ RI-ICD or with lysates of HEK 293 cells transfected with HA-tagged T $\beta$ RI-ICD at $4^{\circ} \mathrm{C}$ for 2 hours. After washing four times with buffer 1, the beads were collected and tested for the bound proteins by immunoblotting with anti-His or antiHA antibody.

\section{Invasion assay}

For invasion assays, we used Corning ${ }^{\circledR}$ BioCoat $^{\mathrm{TM}}$ Matrigel $^{\circledR}$ Invasion Chamber (Corning, Discovery Labware, Bedford, US). The collagen layer of the cell culture inserts was rehydrated by adding $500 \mu \mathrm{l}$ of serum-free RPMI-1640 to the inner compartment, and $1 \times 10^{5}$ cells were seeded inside of each insert in serum-free RPMI-1640 with or without TGF $\beta$. The lower well of the invasion plate was filled with $500 \mu \mathrm{l}$ RPMI supplemented with 10\% FBS. After incubation for 24 hours, non-invasive cells were removed from the interior of the inserts. Invasive cells were photographed using an Olympus BX50 microscope with a $20 \times / 0.5$ objective length after staining with Cell Stain Solution. The images were acquired using CellA software at room temperature, using an Olympus XC30 camera. Each insert was treated with $200 \mu$ of Extraction Solution for 10 minutes. Optical density (OD) at $560 \mathrm{~nm}$ was measured in a plate reader.

\section{Plasmids}

A plasmid encoding C-terminally HA-tagged constitutively active (ca) T $\beta$ RI was a kind gift from Peter ten Dijke (Department of Molecular Cell Biology and Center for Biomedical Genetics, Leiden University Medical Center, Leiden, The Netherlands). Plasmids encoding GFP-tagged APPL1, YFP-tagged APPL1 $(\Delta 1-272)$, and GFP-tagged APPL1 $\Delta \mathrm{C}(\Delta 320-709)$ have been used before [23]. The GFP-T $\beta R I$ plasmid was described before [12].

\section{siRNA transfection}

On TARGET plus siRNA for APPL1 (target sequence: 5' GGAAAUGGACAGUGAUAUA 3'), APPL2 (target sequence: 5' AGAUCUACCUGACCGACAA 3') siRNA, TRAF6 (target sequence: 5' GGCCAUAGG UUCUGCAAAG 3') and non-targeting control siRNA (sequences: 5' UAGCGACUAAACACAUCAA 3'; 5'UAAGGCUAUGAAGAGAUAC 3'; AUGUAUUG GCCUGUAUUAG 3'; 5' AUGAACGUGAAUUGCU CAA 3') were obtained from Dharmacon Research (Lafayette, CO, USA). The siRNA was transfected into cells using Oligofectamine Transfection Reagent (Invitrogen) according to the manufacturer's protocol.

\section{Quantitative real-time PCR (qRT-PCR)}

Total RNA was isolated from PC-3U cells with an RNeasy Mini Kit (Qiagen). Thermoscript RTPCR (Invitrogen) was used for cDNA synthesis. qRTPCR was performed with the Applied Biosystems 7900HT Fast Real-time PCR system and Power SYBR Green (Applied Biosystems) was used for detection of PCR products. The following primers were used for qRT-PCR: MMP2, forward primer (FP), AGGCCGACATCATGGTACTC, reverse primer (RP), GGTCAGTGCTGGAGAAGGTC; MMP9, FP, GCCC TTCTACGGCCACTACT, RP, TCAAAGACCGAGTC CAGCTT; glyceraldehyde-3-phosphate dehydrogenase (GAPDH), FP, TGATGACATCAAGAAGGTGGTGAAG, RP, TCCTTGGAGGCCATGTGGGCCAT. GAPDH was used as an internal control. 


\section{Immunohistochemistry}

The tissue slides were deparaffinized in dimethylbenzene, rehydrated through graded alcohols, and incubated in acidic (R\&D) and Hot Rinse (Biocare Medical) for antigen retrieval in the Retriever 2100 (Proteogenix). After washing in running water, the slides were immersed in 3\% hydrogen peroxide in methanol for 10 minutes to block endogenous peroxidase. After incubation in 5\% goat serum, the sections were incubated overnight at $4{ }^{\circ} \mathrm{C}$ in primary antibody diluted in $5 \%$ goat serum. APPL1 antibody (Cell Signaling) was used at a 1:100 dilution. After washing with PBS, the slides were incubated with secondary antibody (Envision ${ }^{\mathrm{TM}}$ System, Dako) for 30 minutes at room temperature. The sections were washed and developed with DAB Quanto (Thermo Scientific) under microscopic control. The reaction was stopped with tap water, and the sections were stained with hematoxylin, dehydrated, and mounted. Images were acquired with Pannoramic 250 Flash. An ethical permit to use tumour tissues for generation of tissue slides was provided by the Umeå Ethical Review Board in full agreement with the Swedish Ethical Review Act (540/03, Dnr 03-482).

\section{Statistical analysis}

Statistical analyses were performed with SPSS 22 software for Windows. The Mann-Whitney $U$ test was used to analyze differences between two independent groups. Values are expressed as the mean $\pm \mathrm{SD}$ of at least three independent experiments if not otherwise indicated. $P$ values less than 0.05 were considered statistically significant.

\section{ACKNOWLEDGMENTS AND FUNDINGS}

We thank Guangxiang Zang and Wanzhong Wang for assistance with the immunohistochemistry experiments and an introduction into how to evaluate prostate cancer histology.

\section{GRANT SUPPORT}

This work was supported by grants to ML from the Swedish Medical Research Council (K2010 67X-15284-01-3), the Swedish Cancer Society (100303), ALF-VLL-224051, the Kempe Foundation (SMK.1132), the Knut and Alice Wallenberg Foundation (2012.0090), the Cancer Research Foundation in Northern Sweden, Lion's Cancer Research Foundation, and Umeå University.

\section{Author contributions}

J.S and Y.M. contributed equally to this work. J.S.performed the nuclear fractionation assays, immunoprecipitation, immunohistochemistry, invasion assays, quantitive RT-PCR and Brightfield PLA on tissue sections. Y.M. performed immunofluorescence experiments, in vitro binding assays, immunofluorescence PLA and Brightfield PLA on cells. M.L investigated the immunostaining on the tissue sections and supervised the project. All the authors analyzed, discussed data and prepared the manuscript.

\section{CONFLICTS OF INTEREST}

The authors declare no conflicts of interest.

\section{Editorial note}

This paper has been accepted based in part on peer-review conducted by another journal and the authors' response and revisions as well as expedited peer-review in Oncotarget.

\section{REFERENCES}

1. Esfahani M, Ataei N, Panjehpour M. Biomarkers for Evaluation of Prostate Cancer Prognosis. 2015; 16:2601-2611.

2. Jones E, Pu H, Kyprianou N. Targeting TGF-beta in prostate cancer: therapeutic possibilities during tumor progression. Expert Opin Ther Targets. 2009; 13:227-234.

3. Shi Y, Massagué J. Mechanisms of TGF-beta signaling from cell membrane to the nucleus. Cell. 2003; 113:685-700.

4. Heldin $\mathrm{C}-\mathrm{H}$, Landström M, Moustakas A. Mechanism of TGF-beta signaling to growth arrest, apoptosis, and epithelial-mesenchymal transition. Curr Opin Cell Biol. 2009; 21:166-176.

5. Massagué J. TGF $\beta$ signalling in context. Nat Rev Mol Cell Biol. 2012; 13:616-630.

6. Derynck R, Muthusamy BP, Saeteurn KY. Signaling pathway cooperation in TGF- $\beta$-induced epithelialmesenchymal transition. Curr Opin Cell Biol. 2014; 31:56-66.

7. Itoh F, Watabe T, Miyazono K. Roles of TGF- $\beta$ family signals in the fate determination of pluripotent stem cells. Semin Cell Dev Biol. 2014; 32: 98-106.

8. Mu Y, Gudey SK, Landström M. Non-Smad signaling pathways. Cell Tissue Res. 2012; 347:11-20.

9. Zhang L, Zhou F, ten Dijke P. Signaling interplay between transforming growth factor- $\beta$-receptor and PI3K/AKT pathways in cancer. Trends Biochem Sci. 2013; 38:612-620.

10. Sorrentino A, Thakur N, Grimsby S, Marcusson A, von Bulow V, Schuster N, Zhang S, Heldin C-H, Landström M. The type I TGF-beta receptor engages TRAF6 to activate TAK1 in a receptor kinase-independent manner. Nat Cell Biol. 2008; 10:1199-1207.

11. Yamashita M, Fatyol K, Jin C, Wang X, Liu Z, Zhang YE. TRAF6 mediates Smad-independent activation of JNK and p38 by TGF-beta. Mol Cell. 2008; 31:918-924. 
12. Mu Y, Sundar R, Thakur N, Ekman M, Gudey SK, Yakymovych M, Hermansson A, Dimitriou H, BengoecheaAlonso MT, Ericsson J, et al. TRAF6 ubiquitinates TGF $\beta$ type I receptor to promote its cleavage and nuclear translocation in cancer. Nat Commun. 2011; 2:330.

13. Gudey SK, Sundar R, Mu Y, Wallenius A, Zang G, Bergh A, Heldin C-H, Landström M. TRAF6 stimulates the tumorpromoting effects of TGF $\beta$ type I receptor through polyubiquitination and activation of presenilin 1. Sci Signal. 2014; 7:ra2.

14. Sorkin A, von Zastrow M. Endocytosis and signalling: intertwining molecular networks. Nat Rev Mol Cell Biol. 2009; 10:609-622.

15. Di Guglielmo GM, Le Roy C, Goodfellow AF, Wrana JL. Distinct endocytic pathways regulate TGF-beta receptor signalling and turnover. Nat Cell Biol. 2003; 5:410-421.

16. Mitchell H, Choudhury A, Pagano RE, Leof EB. Liganddependent and -independent transforming growth factor- $\beta$ receptor recycling regulated by clathrin-mediated endocytosis and rab11. Mol Biol Cell. 2004; 15:4166-4178.

17. Yakymovych I, Yakymovych M, Zang G, Mu Y, Bergh A, Landstrom M, Heldin C-H. CIN85 modulates TGF $\beta$ signaling by promoting the presentation of TGF $\beta$ receptors on the cell surface. J Cell Biol. 2015; 210:319-332.

18. Panopoulou E, Gillooly DJ, Wrana JL, Zerial M, Stenmark H, Murphy C, Fotsis T. Early endosomal regulation of Smaddependent signaling in endothelial cells. J Biol Chem. 2002; 277:18046-18052.

19. Christoforidis S, McBride HM, Burgoyne RD, Zerial M. The Rab5 effector EEA1 is a core component of endosome docking. Nature. 1999; 397:621-625.

20. Mellor P, Furber LA, Nyarko JNK, Anderson DH. Multiple roles for the $\mathrm{p} 85 \alpha$ isoform in the regulation and function of PI3K signalling and receptor trafficking. Biochem. J 2012; 441:23-37.

21. Mitsuuchi Y, Johnson SW, Sonoda G, Tanno S, Golemis EA, Testa JR. Identification of a chromosome 3p14.3-21.1 gene, APPL, encoding an adaptor molecule that interacts with the oncoprotein-serine/threonine kinase AKT2. Oncogene. 1999; 18:4891-4898.

22. Zoncu R, Perera RM, Balkin DM, Pirruccello M, Toomre D, De Camilli P. A phosphoinositide switch controls the maturation and signaling properties of APPL endosomes. Cell. 2009; 136:1110-1121.

23. Miaczynska M, Christoforidis S, Giner A, Shevchenko A, Uttenweiler-Joseph S, Habermann B, Wilm M, Parton RG, Zerial M. APPL proteins link Rab5 to nuclear signal transduction via an endosomal compartment. Cell. 2004; 116:445-456.

24. Yang L, Lin H-K, Altuwaijri S, Xie S, Wang L, Chang C. APPL suppresses androgen receptor transactivation via potentiating Akt activity. J Biol Chem. 2003; 278:16820-16827.
25. Hupalowska A, Pyrzynska B, Miaczynska M. APPL1 regulates basal NF- $\kappa \mathrm{B}$ activity by stabilizing NIK. J Cell Sci. 2012; 125:4090-4102.

26. Banach-Orlowska M, Pilecka I, Torun A. Functional characterization of the interactions between endosomal adaptor protein APPL1 and the NuRD co-repressor complex. Biochem J. 2009; 423:389-400.

27. Scita G, Di Fiore PP. The endocytic matrix. Nature. 2010; 463:464-473.

28. Liu J, Yao F, Wu R, Morgan M, Thorburn A, Finley RL, Chen YQ. Mediation of the DCC apoptotic signal by DIP13 alpha. J Biol Chem. 2002; 277:26281-26285.

29. Varsano T, Dong M-Q, Niesman I, Gacula H, Lou X, Ma T, Testa JR, Yates JR, Farquhar MG. GIPC is recruited by APPL to peripheral TrkA endosomes and regulates TrkA trafficking and signaling. Mol Cell Biol. 2006; 26:8942-8952.

30. Deepa SS, Zhou L, Ryu J, Wang C, Mao X, Li C, Zhang N, Musi N, DeFronzo RA, Liu F, et al. APPL1 mediates adiponectin-induced LKB1 cytosolic localization through the PP2A-PKCzeta signaling pathway. Mol Endocrinol $2011 ; 25: 1773-1785$.

31. Bidkhori G, Narimani Z, Hosseini Ashtiani S, Moeini A, Nowzari-Dalini A, Masoudi-Nejad A. Reconstruction of an Integrated Genome-Scale Co-Expression Network Reveals Key Modules Involved in Lung Adenocarcinoma. PLoS One. 2013; 8:e67552.

32. Deepa SS, Dong LQ. APPL1: role in adiponectin signaling and beyond. Am J Physiol Endocrinol Metab. 2009; 296:E22-E36.

33. Söderberg O, Gullberg M, Jarvius M, Ridderstråle K, Leuchowius K-J, Jarvius J, Wester K, Hydbring P, Bahram F, Larsson L-G, et al. Direct observation of individual endogenous protein complexes in situ by proximity ligation. Nat Methods. 2006; 3:995-1000.

34. Ikeda F, Crosetto N, Dikic I. What determines the specificity and outcomes of Ubiquitin signaling? Cell. 2010; 143:677-681.

35. Mosesson Y, Mills GB, Yarden Y. Derailed endocytosis: an emerging feature of cancer. Nat Rev Cancer. 2008; 8: 835-850.

36. Mellman I, Yarden Y. Endocytosis and Cancer. Cold spring Harb Perspect Biol. 2013; 5:a016949.

37. Rashid S, Pilecka I, Torun A, Olchowik M, Bielinska B, Miaczynska M. Endosomal adaptor proteins APPL1 and APPL2 are novel activators of beta-catenin/TCF-mediated transcription. J Biol Chem. 2009; 284:18115-18128.

38. Schenck A, Goto-Silva L, Collinet C, Rhinn M, Giner A, Habermann B, Brand M, Zerial M. The endosomal protein Appl1 mediates Akt substrate specificity and cell survival in vertebrate development. Cell. 2008; 133:486-497.

39. Pyrzynska B, Banach-Orlowska M, Teperek-Tkacz M, Miekus K, Drabik G, Majka M, Miaczynska M. Multifunctional protein APPL2 contributes to survival of human glioma cells. Mol Oncol. 2013; 7:67-84. 
40. Tan Y, You H, Wu C, Altomare DA, Testa JR. Appl1 is dispensable for mouse development, and loss of Appll has growth factor-selective effects on Akt signaling in murine embryonic fibroblasts. J Biol Chem. 2010; 285:6377-6389.

41. Johnson IRD, Parkinson-Lawrence EJ, Shandala T, Weigert R, Butler LM, Brooks DA. Altered Endosome Biogenesis in Prostate Cancer Has Biomarker Potential. Mol Cancer Res. 2014; 12:1851-1862.

42. Jacob A, Prekeris R. The regulation of MMP targeting to invadopodia during cancer metastasis. Front Cell Dev Biol. 2015; 3:1-9.

43. Rashid S, Parveen Z, Ferdous S, Bibi N. Mutually exclusive binding of APPL $(\mathrm{PH})$ to BAR domain and Reptin regulates $\beta$-catenin dependent transcriptional events. Comput Biol Chem. 2013; 47:48-55.

44. Chandra M, Zang S, Li H, Zimmerman LJ, Champer J, Tsuyada A, Chow A, Zhou W, Yu Y, Gao H, et al. Nuclear translocation of type I transforming growth factor $\beta$ receptor confers a novel function in RNA processing. Mol Cell Biol. 2012; 32:2183-2195.
45. Sundar R, Gudey SK, Heldin C-H, Landström M. TRAF6 promotes TGF $\beta$-induced invasion and cell-cycle regulation via Lys63-linked polyubiquitination of Lys178 in TGF $\beta$ type I receptor. Cell Cycle. 2015; 14:554-565.

46. Franzén P, Ichijo H, Miyazono K. Different signals mediate transforming growth factor-beta 1-induced growth inhibition and extracellular matrix production in prostatic carcinoma cells. Exp Cell Res. 1993; 207:1-7.

47. Edlund S, Bu S, Schuster N, Aspenstrom P. Transforming Growth Factor- $\beta 1$ (TGF $\beta$ )- induced Apoptosis of Prostate Cancer Cells Involves Smad7-dependent activation of p38 by TGF- $\beta$-activated kinase 1 and mitogen-activated Protein Kinase Kinase. 2003; 3. 14:529-544.

48. Edlund S, Lee SY, Grimsby S, Zhang S, Heldin C. Interaction between Smad7 and $\beta$-catenin: importance for transforming growth factor $\beta$-induced apoptosis. 2005; $25: 1475-1488$. 